and the Fritz Progl prize to Dr. Moriz Niessner for his micro-analytical investigations on alloys.

\section{Imperial Academy of Japan}

At a meeting of the Imperial Academy of Japan on May 10, annual medals and prizes were awarded to the following: Kyosuke Kindaichi for his studies on the Ainu epic "Yukar"; Kiyoo Wadati for his investigations on deep focus earthquakes; Ikutaro Hirai for his work on the cause of the meningitislike disease frequently observed among Japanese suckling children ; Tatuo Aida for genetical studies on the body colour of Aplocheilus latipes; Motojiro Matuyama for his geophysical investigations on gravity anomalies and magnetism of basaltic rocks; Shintaro Uda for research on ultra-short electro-magnetic waves. Tho Mendenhall Memorial Prize was awarded to Seishi Kikuchi for his studies on the diffraction of electron rays through thin mica plates.

\section{Visceral Sense Organs}

ThE fourth Victor Horsley Memorial Lecture was delivered on July 20 in the Medical School of University College Hospital by Prof. E. D. Adrian, who discussed the "Visceral Sense Organs". The action of the sense organs in the lungs and in the great blood vessels can be studied by recording the nervous messages which they send to the brain stem, a method made possible by the use of valve amplification to magnify the electric changes in the sensory nerve fibres. The normal sensory discharges in the vagus and carotid sinus nerves were demonstrated by gramophone records in which the nerve impulses were converted into sounds varying in pitch with the frequency of the discharge. The sense organs in the lung resemble the muscle spindles, giving a rhythmic discharge of impulses so long as the tissues are stretched. In normal breathing the discharge only occurs at inspiration, but there are some endings which are excited by collapse of the lung, and these may be the cause of rapid breathing in pathological conditions. The sense organs in the aorta and sinus caroticus behave like those in the lung and give a faithful signal of the blood pressure. Both systems act as governors to keep the respiratory and vascular systems working within safe limits, and, as with all sense organs, their effect depends upon messages which are graded by changes in impulse frequency and in the number of units in action.

\section{New Motor-Boat Record}

ON July 18, Mr. Kaye Don, piloting Lord Wakefield's motor-boat Miss England III, twice broke the previous world's speed record for motor-boats. In his first attempt Mr. Don covered the measured mile in $35.4 \mathrm{sec}$. and $35.2 \mathrm{sec}$. ( 117.43 miles an hour), and in the second attempt his times were 34.4 sec. and 34.8 sec. (119.81 miles an hour). The previous record was set up by Mr. Garfield A. Wood, who achieved 111.71 miles an hour. Sir Henry Segrave's record on Lake Windermere when he was killed in 1930 was 98.96 miles an hour. Miss England $I I I$ was designed and built by Messrs. John Thornycroft and Co., Ltd., at Hampton-on-Thames. It is a single-step vessel and is fitted with two propellers. The boat is fitted with two Schneider Trophy type supercharged Rolls-Royce engines, developing 2200 h.p. and consuming about five gallons of fuel a minute. The length of the hull of the boat is $35 \mathrm{ft}$., and the maximum beam is $9 \mathrm{ft} .6 \mathrm{in}$.

\section{High Speed and Flight}

A series of comprehensive experiments upon the possibilities of high-speed flight has been carried out in the langley Field High Speed Wind Tunnel of the Nationul Advisory Committee for Aeronautics in the U.S.A. Air speeds up to 800 miles an hour, which is faster than the speed of sound, have been reached. It has been definitely established that with the present conventional form of wing section there is so great an increase in drag at about 600 miles an hour that it will be impossible to carry sufficient power to overcome it, assuming the present methods of conversion of fuel to air thrust. This is confirmed by experience with high-speed propellers, the blade tips of which may easily be travelling at a peripheral speed approaching the velocity of sound. In such cases their outer portions may be actually exerting a negative effect. The delicate mechanisms of the human body do not appear to be susceptible to stearly high speeds, but they react to accelerations at much lower figures. 'Ihis case arisos often during flight, when every turn is an angular acceleration. It has been establishod that the maximum speed that the human borly can stand during an average sharp turn is about 300 miles por hour. The present speed record for flight in a straight, line is an average $\mathbf{4 0 8 . 8}$ miles an hour, although speeds up to 415.2 miles an hour for short periods have boen recorded.

\section{Constitutional Tendencies in the Orient}

At a time when a bold experiment in the method of governing India is to be made and the details of the new federal constitution are being elaborated, a thoughtful pajer by Sir Amold Wilson, in the English Review for May, on the relative merits of government by means of an executive responsible to an elected body and by bureaucratic methods, should be read. As is woll known, the application of the democratic principle to Fastern conditions is by no means new. It has already been attempted, not only in the management of local affairs in India itself, but also in a wider field in other countries, such as Turkoy, Ezypt, Persia, Iraq, Cyprus, Ceylon, and the Dutch East Indies. The results so far obtained are described in detail in the paper under roview. They make very melancholy reading. In these very differont localities, the introduction of the electoral principle has almost without exception either ended in complete failure or has been disappointing. On the othor hand, in the overseas possessions of France and Italy, where the system adopted is a benevolent autocracy, the people are said to be contented and there is little or no unrest of the type now so common throughout India.

\section{The Indian Problem}

IT is difficult to resist the conclusion that had the Indian problern been approached at the very outset by the methods familiar to the man of science, one of 
the first tasks would have been a careful study of the literature of the subject and particularly of the results already obtained from the experiments in the art of ruling which have been made in other countries. This procedure, however, does not appear to have been followed. Even the Commission which recently worked under the able guidance of Sir John Simon was not empowered to study constitutional developments in other Asiatic countries, otherwise " they might well have hesitated before recommending even a moderate extension of the franchise". The matter, however, has gone too far for such studies to be undertaken. The new constitution will shortly be established : the results will soon be clear to all. If it succeeds, all criticism will be laid to rest by the one unanswerable argument--success. If it fails, a new Indian Civil Service, in which it is hoped that science will take its proper place, will have to be re-established.

\section{A High-Efficiency Gaseous Lamp}

MessRs. Philips Lamps, Ltd., are introducing a new lamp which has an efficiency of about eight times that of a gas-filled lamp taking the same power. A description of the lamp is given in the Electrical Times for July 14. In the new lamp an electric discharge passes through a rare gas ' filling ' with a small quantity of metallic sodium. There is an oxide cathode with one or two anodes. The bulb of the lamp is in the shape of a cylinder, which has to be heated up to a certain temperature sufficient to vaporise the sodium. The lamp is enclosed in a second cylinder, which accelerates the heating and keeps the temperature constant. The discharge and consequently the emission of light depend mainly on the sodium vapour. The colour of the light is yellow and practically monochromatic. This colour is favourable to good visibility and therefore the lamp is very suitable for street lighting. A photograph taken at night is shown of a long length of road in Holland illuminated by the new gaseous lamps. It has been noticed that drivers of fast cars when entering the newly lighted part of the road switched off their headlights unasked. Hence there is no 'dazzle', the elimination of which is one of the greatest problems of night driving. The candlepower of the lamps is $500-600$ for the smallest size made, which take 100 watts. These lamps will be useful where colour is of minor importance. For domestic use a whiter light is more desirable.

\section{Modern Developments in Precision Clocks}

THE most accurate timekeepers of to-day are divided into two classes, depending on whether the restoring force of the oscillator is gravity, as in pendulum clocks, or elasticity, as in quartz crystal oscillators. In a monograph by A. L. Loomis and W. A. Marrison on precision clocks, published in the Transactions of the American Institute of Electrical Engineers, an account is given of the performance of a set of 100,000 -cycle quartz oscillators built by the Bell Telephone Laboratories for use as a primary frequency standard. The frequency of quartz oscillators is practically independent of the amplitude. They are not affected by gravity or magnetic fields and can be easily shielded from electrostatic fields. They are practically unaffected by heavy traffic in neighbouring roads or by the vibrations near earthquake zones. A crystal clock standard is more costly than a pendulum clock of the highest precision, but it can be used for many purposes. For example, an absolute comparison of crystal clocks can be made with an error of less than one hundred-thousandth part of a second, and can be maintained continuously. For short time comparisons an inaccuracy not greater than 1 in $10^{10}$ has been obtained. The high accuracy of comparison is due chiefly to the fact that the number of vibrations is 200,000 times greater than with a 'seconds' pendulum. A comparison made of the data obtained by observing the difference in the rates of a crystal clock and three pendulum clocks revealed for the first time a lunar day variation. This is due to the fact that the crystal does not respond to variations in the gravitational effect of the moon, while the pendulum does. The difference in the rates of the clock and the crystal timekeeper thus contains a term depending on the period of the lunar day.

\section{Jubilee of the Ferranti Works}

THe late Dr. S. Z. de Ferranti at the age of eighteen was the principal founder of the original company of Ferranti, Thomson and Ince in Charterhouse Square, London, in 1882. It is a little difficult to realise that there was then a great demand for electric meters. Messrs. Ferranti, Ltd., now of Hollinwood, Manchester, held an exhibition at Bush House, London, during June to commemorate their jubilee. The fifty years' life-story of the firm shown by the historical exhibits is largely a history of the development of public electricity supply. A particularly interesting exhibit was the earliest models of Ferranti meters, some of which have only recently been taken out of service. The new methods of hardening the pivots and burnishing them so as to get the exact shape with the help of a micrometer jewel examiner with a powerful microscope were shown in action. New devices rendered necessary by the 132-kilovolt grid scheme in Great Britain were shown in action. An even more recent development is the manufacture of electric clocks, which are now made quite cheaply, of all sizes and shapes with cases of bakelite, wood, or metal. A prominent feature of the radio exhibit was a new seven-valve receiving set. A full range of water heaters and fires were shown. A working model of the Ferranti hot-water system for a house employing those heaters was shown. The 'Era' fire which Ferranti's make is said to be ideal for devices for hatching chickens (chicken brooders). The machines used at the Ferranti works in Hollinwood are of the most modern design, and employ more than five thousand workmen.

\section{Tuberculosis in England and Wales}

The Report on Tuberculosis by Dr. A. S. MacNalty to the Ministry of Health (Reps. on Pub. Health and Med. Subjects, No. 64. H.M. Stationery Office. 3s. net.) may be regarded as an 'audit' of the present position of the tuberculosis question in Great Britain. Tuberculosis is a disease not only of medical interest but also of wide sociological and economic importance. Anti-tuberculosis measures cost the country a great deal; for example, some $2 \frac{1}{2}$ million 